Peer-Reviewed Article

ISSN: 2162-3104 Print/ ISSN: 2166-3750 Online

Volume 7, Issue 3 (2017), pp. 671-686

(C) Journal of International Students

http://jistudents.org/

doi: 10.5281/zenodo.570032

\title{
Sources of Social Support Among International College Students in the United States
}

\author{
Amir Bhochhibhoya \\ Yue Dong \\ Paul Branscum \\ University of Oklahoma, USA
}

\begin{abstract}
International students are challenged due to the abrupt change in social support. The purpose of this study was to operationalize different sources of social support and evaluate determinants of mental health among international students $(n=328)$. An instrument was developed to measure four distinct sources of social support. Repeated measures ANOVA were used to evaluate statistical differences. Results found significant mean differences between each type of social support with social support from: family/friends currently living in their home country highest and friends/families living and born in the U.S. lowest. These findings provide evidence on the applicability of this new instrument. The depth in which social support is defined in this study can reflect the greater context in future research findings.
\end{abstract}

Keywords: International students, Mental Health, Social Support, Study Abroad, Type D

With approximately $22 \%$ share of the international student market, the United States has hosted the highest number of international students compare to any other country in the world (Verbik \& Lasanowski, 2007). The trend of international students coming to the United States has increased ever since World War II (Das, chow, \& Rutherford, 1986; Sandhu, 1995). To illustrate, in 1950-51 it was reported that there were a total of 29,813 international students, while this number increased to 886,052 in 2013-14 (Institute of International Education, 2015; United Nations Educational, Scientific and Cultural Organization, 1965). The increase in cultural diversity has been markedly reflected in the U.S. educational system and contributed to draw more international students every year (Institute of 
International Education, 2015). Renowned educational institutions, advanced research opportunities, exposure to the world's largest economy, and networking opportunities with students from all over the world, continue to attract hundreds of thousands of students every year. Concurrently, international students promote cultural diversity to universities and local communities by bringing different perspectives into classrooms, research labs, and society at large. International students also provide over $\$ 27$ billion dollars of revenue to the U.S. economy through tuition and living expenses (National Association of Foreign Student Advisers, 2014). After graduation, some international students continue to contribute to the American economy by entering the American workforce. The National Science Foundation (2008) suggested nearly half of international students who earned a U.S. doctoral degrees in Science and Engineering during 2002-2005 accepted employment offers in the United States.

Despite having different nationalities, ethnicities, religions, and political backgrounds, all international students share certain characteristics. For example, all international students are introduced to a new academic setting with many unfamiliar aspects. They also encounter cultural differences while interacting with other students, professors, and surrounding communities, which require behavioral and attitudinal adjustments. Other major stressors for international students include language barriers, difficulty in socio-cultural adaptation, discrimination, and financial constraints (Smith \& Khawaja, 2011). Evidence suggests these factors frequently place international students at greater risk for psychological problems, such as depression and poor psychological well-being, compared to American-born college students (Atri, Sharma, \& Cottrell, 2007; Jung, Hecht, \& Wadsworth, 2007; Wei et al., 2007).

Because international students leave friends and families behind, these students oftentimes feel a deep sense of loss and loneliness (McClure 2007; Sawir, Marginson, Deumert, Nyland, \& Ramia, 2008; Zhao et al., 2008). These students are also challenged to establish comparable social networks to provide social support due to language and cultural barriers and interpersonal problems (Yeh \& Inose, 2003). Social support typically validates one's self-identity, self-esteem, and self-concept; it also provides necessary emotional and instrumental support. Consequently, the loss of social support can lead to feelings of isolation or disorientation (Pedersen, 1991). A study conducted by Mallinckrodt and Leong (1992) suggested that social support not only has a direct positive correlation with stress reduction but also acts as a buffering effect when international students experience psychological distress.

International students are constantly trying to adapt to new living conditions that encompass a change in the built environment, and a lack of 
social support. This dual disparity for international students could result in chronic stress which can manifest into other health problems, such as impairments to the immune system and an intensified susceptibility to illnesses (Cohen, Janicki-Deverts, \& Miller, 2007; Mori, 2000). Therefore, it is not unusual to see that international students report sleep deprivation, loss of appetite, and lack of stamina and energy, as well as higher rates of headaches and gastrointestinal problems (Mori, 2000). These physiological symptoms may accompany with psychological distress such as sadness, loss, disappointment, resentment, guilt, helplessness, hopelessness, homesickness, painful feelings of isolation, and loneliness (Mori, 2000; Wei et al., 2007). Sometimes these negative psychological feelings are expressed in harmful ways such as anger and hostility towards either the American culture or their own native culture.

Clonninger et al., (2009) defined personality as the dynamic individual makeup of one's psycho-biological system that helps them adapt to a changing environment (Clonninger \& Svrakic, 2009). Type D personality has recently attracted much attention in health promotion and refers to a joint tendency of one's predisposition towards social inhibition (SI) and negative affectivity (NA) (Bruce, Curren, \& Williams, 2012). SI refers to an individual's tendency to inhibit their emotional expression and behaviors towards social situations and $N A$ refers to an individual's tendency towards experiencing negative emotions and poor self-concept. Examples of SI are reticence and lack of self-assurance whereas examples of NA are worring, being irritable, and feeling gloomy in a range of situations (Denollet et al., 1996). Studies have associated Type D personality with chronic health issues (e.g., cardiovascular diseases) and unhealthy behaviors (e.g., alcohol consumption, smoking, and lack of physical activity), and it has also been found as a good indicator of psychological distress (Bhochhibhoya, Collado, Branscum, \& Sharma, 2014; Denollet, Sys, \& Brutsaert, 1995; Emons, Meijer, \& Denollet, 2007; Gilmour \& Williams, 2012; Mols, 2012; Mols \& Denollet, 2010; Schiffer et al., 2005; Williams et al., 2008 ).

International students live far from their family and friends and oftentimes depend on social support different sets of social networks, which is distinct from their American counterparts whose family and friends are close. Thus, the purpose of this study was to extend the definition of social support and operationalize it for international students. This study identifies distinct sources of social support available to international students such as social support from family and/or friends: (a) living in their home country, (b) residing in the United States that was originally from their home country, (c) residing in the United States that was originally from other countries (other than the home country and the United States), and (d) living in the local community and born in the United States. Identifying the sources of social support will help health practitioners and policy makers understand 
this population to a greater extent, and information from this study can be potentially used to promote mental health and quality of life among this population. This study also explores Type D personality among international students, which to date, has not been explored in the literature.

\section{METHOD}

\section{Research Design and Study Sample}

This study used a cross-sectional design with a convenience sample of international students $(N=328)$ from a large southwestern public university. Data were collected using an online survey (qualtrics.com). An email with the link to the survey was sent to all international students from a listserv provided from the university's international student services office. Participants were asked to read the study details and provide consent if they agree to participate in the study. Only students who provided consent to participate were allowed to take the survey. All participants were entered into a raffle to win a $\$ 50$ gift card to a business of their choice. The Institutional Review Board approved this study.

For the purpose of the study, a priori sample size was calculated using the following parameters for a repeated measures ANOVA ( $\mathrm{G}^{*}$ Power): a medium effect size $(f=0.25)$; an alpha of .05 ; power of $80 \%$; four groups; and correlation among repetitive measures of 0.5 (Cohen et al., 2013). Based on the input, a sample size of 82 was determined to be adequate. However, since a new instrument was developed in this study, factor analysis was conducted for data reduction by seeking underlying latent (unobservable) variables that were reflected in the manifest (observed) variables. Comrey and Lee's (2013) advised the following sample size for the factor analysis: 50 is very poor, 100 is poor, 200 is fair, 300 is good, 500 is very good, and 1000 more is excellent. Following both suggestions, the sample size collected in this study $(N=328)$ provided adequate power to find expected effect sizes and was considered 'good' for factor analysis.

\section{Instrumentation}

Type D Scale (DS14). Denollet's Type D personality scale consists of 14 items: seven items to assess negative affectivity and seven items to assess social inhibition. Each item uses a five-point Likert scale scored $(1=$ false, 2 = rather false, $3=$ neutral, $4=$ rather true, and $5=$ true). Example items for negative affectivity are "I often make a fuss about unimportant things" and "I often find myself worrying about something". Example items for social inhibition include "I find it hard to start a conversation" and "I am a closed kind of person". Scores for each subscale range from 7 to 35, with a higher score indicating a higher risk for experiencing NA and SI. As suggested by Denollet (1996), a cut-off of 17 can be used to dichotomize participants: Scores $\geq 17$ indicate Type D/NA or Type D/SI personality and scores $\leq 17$ 
indicate non-Type D/NA or non-Type D/SI personality. The DS14 is considered to be a valid and reliable scale to detect Type D personality and the current results confirmed the internal consistency of NA sub-scale and SI sub-scale are high. The Cronbach alpha coefficient for Type D/NA subscale and Type D/SI subscale in the study has been found to be 0.85 and 0.83 respectively.

Social Support Questionnaire. In a review of available instruments evaluating social support, none were found that evaluated distinct sources of social support for international students, therefore a new instrument was developed (Cohen, Mermelstein, Kamarck, \& Hoberman, 1985; Schuster, Kessler, \& Aseltine Jr, 1990); Seeman, Berkman, Blazer, \& Rowe, 1994). The survey development process and psychometric properties is elaborated in following paragraph. To develop a new instrument, four distinct sources of social support were constitutively defined, and included social support from: (a) close individuals (friends and/or family) currently living in their home country (e.g., parents still living in their home country), (b) close individuals (friends and/or family) residing in the United States that were originally from their home country (e.g., siblings that currently live in the United States.), (c) close individuals residing in the United States that were originally from other countries (e.g., international students at the same university, but from another country than their own), and (d) close individuals (friends and/or family) living in the local community, born in the United States (e.g., other college students born in the United States). Using House's (1981) definition of social support, 4 types of social support were evaluated from each group, which included: emotional support (love and caring support), appraisal support (receiving evaluative assistance), informational support (receiving suggestions and guidance), and instrumental support (receiving tangible assistance). Items on each scale were evaluated on a five-point Likert scale $(1=$ Never to $5=$ Always $)$. An example item for each scale includes: "I depend on people close to me (friends and/or family) living in my home country for love?" (emotional support); "I depend on people close to me (friends and/or family) living in my home country for praise on my success?" (appraisal support); "I depend on people close to me (friends and/or family) living in my home country for counsel?" (informational support); "I depend on people close to me (friends and/or family) living in my home country for money or other financial support?" (instrumental support). Eight items evaluated each source of social support, and each scale of social support ranged from 8 to 40 , with a higher score indicating a higher degree of social support and lower score indicated a lower degree of social support from each source.

In addition, demographic items such as age, sex, length of stay in the U.S., nationality, year in college, major, and approximate GPA were also included in the questionnaire. 


\section{Survey Development}

As aforementioned, a new questionnaire was developed to evaluate 4 sources of social support. After the items were developed for the survey, the survey was submitted to an expert panel of professors having expertise in the areas of instrument development, social support, and the target population (international college students) to evaluate face and content validity, and readability. The review included a two round process. A small pilot study was also conducted with a sample of international students $(n=10)$ to ensure readability.

The psychometrics of the instrument were evaluated using Cronbach's alpha scores to establish internal consistency reliability, and factor analysis to confirm each scale contained a one-factor solution. Dilorio (2006) suggests that items on the same scale should correlate $(r)$ between 0.20 and 0.80 , and an overall alpha score $\geq 0.70$ is considered internally reliable'. All of the social support scales were found to be internally consistent [close people living in the home country $(\alpha=.845)$, close people residing in the U. S. that were originally from the home country $(\alpha=.912)$, close people residing in the United States that were originally from other than home countries $(\alpha=.919)$, and close people living in local community and born in the United States $(\alpha=.934)]$. In addition, confirmatory factor analysis using maximum likelihood estimation was used to determine to construct validly for each sub-scale of social support questionnaire. Eigenvalues and scree plots (from 4.971 to 5.496) indicated a one-factor solution for each construct subscale and each item loaded significantly on its given dimension of social support, except for social support from people living in a home country which resulted a two-factor solution. After closely analyzing the factor loadings there was no obvious cluster for the 2-factor solution, thus, further analysis was considered without removing any items from this subscale.

\section{Data Analysis}

Descriptive statistics and standard deviations were first calculated to summarize responses. Any data that is outside \pm 3 standard deviation value were considered as outlier and was reviewed for data entry error. If the outlier data was not the result of data entry, it was replaced with the mean value. Repeated measures ANOVA's with four levels were used to evaluate mean differences between each source of social support, and bivariate correlations were computed to explore associations between each source of social support. A linear regression model was next used to determine the effects of length of stay in the United States to four sources of social support, and to determine the effects of length of stay in the United States towards negative affectivity and social inhibition. A p-value of 0.05 was used to determine statistical significance and Cohen's $d$ was used to determine 
practical significance (effect size), determined as small $(d=0.20)$, medium ( $d$ $=0.50)$ and large $(d=0.80)$ effects (Cohen, 1992). All data was analyzed using SPSS (Version 19.0).

\section{RESULTS}

The study sample contained almost an equal number of men $(n=148 ; 45.1 \%)$ and women $(\mathrm{n}=180 ; 54.9 \%)$, and the average age of the participants was 25.38 years $( \pm 5.48)$ ranging from $17-56$ years old. Current year in school ranged from freshman to $\mathrm{PhD}$ (freshman $=6.1 \%$, sophomore $=7.9 \%$, junior $=13.1 \%$, senior $=16.2 \%$, Masters $=28.4 \%, \mathrm{PhD}=25.3 \%$, other $=3 \%$ ). Responses came from international students representing 72 countries, with the highest representation from China (18.9\%), India (8.2\%), and Colombia (5.2\%). With regards to Type D personality, $51.2 \%$ were categorized with negative affectivity, and $57.3 \%$ were categorized with social inhibition. The participant's average stay in the United States during the study was 3.66 years ( \pm 2.95 years) and ranged from 1 to 17 years.

Table 1. Demographic information of gender, race, and year in college as assessed by demographic profile and summary of Type $D$ personality variable as assessed by DS-14.

\begin{tabular}{ll}
\hline Variables & Total (n)(\%) \\
\hline Gender & $148(45.1)$ \\
Male & $180(54.9)$ \\
Female & \\
Year in College & $20(6.1)$ \\
$1^{\text {st }}$ year (Freshman) & $26(7.9)$ \\
$2^{\text {nd }}$ year (Sophomore) & $43(13.1)$ \\
$3^{\text {rd }}$ year (Junior) & $53(16.2)$ \\
$4^{\text {th }}$ or more years (Senior) & $93(28.4)$ \\
Masters & $83(25.3)$ \\
PhD & $10(3)$ \\
Other & \\
Type D personality & $168(51.2)$ \\
Negative Affectivity (Yes) & $188(57.3)$ \\
Social Inhibition (Yes) &
\end{tabular}

Mean scores for social support varied from close people living in the home country $(25.25 \pm 6.87)$, close people residing in the United States that were originally from the home country $(21.13 \pm 8.14)$, close people residing in the United States that were originally from other countries (17.42 \pm 7.54$)$, and close people living in local community and born in the United States (17.37 18.04$)$. Results from the repeated measure ANOVA found a 
significant mean difference between each source of social support [F (2.808, $\left.918.227)=112.342, \eta p^{2}=0.256, p<0.01\right]$, and pairwise comparisons suggested that social support from close people living in the home country was significantly higher than social support from close people residing in the United States that were originally from the home country $(p<0.01$, Cohen's $d=0.54$ ), close people residing in the United States that were originally from other countries $(p<0.01$, Cohen's $d=1.08)$, and close people living in local community and born in the United States $(p<0.01$, Cohen's $d=1.05)$. Similarly, social support from close people residing in the United States that were originally from the home country was significantly higher than social support from close people residing in the United States that were originally from other countries $(p<0.01$, Cohen's $d=0.47)$ and close people living in local community and born in the United States $(p<0.01$, Cohen's $d=0.46)$. However, social support from close people residing in the United States that were originally from other countries and close people living in the local community and born in the United States was not found to be significantly different $(p>0.05)$.

Pearson correlations between four sources of social support indicated that all correlations were statistically significant $(p<0.05)$, ranging from 0.371 to 0.143 . The Pearson correlations also suggested that students who depended on close people living in home country for social support are also inclined to depend on close people residing in the United States that were originally from the home country, as well as close people residing in the United States that were originally from other countries compared to close people living in local community and born in the United States. Pearson correlations were also computed between participants' duration of the stay in the United States and each source of social support. Results indicated that duration of stay in the United States was negatively associated $(r=-0.139, p$ $=0.012$ ) with social support from close people living in the home country and positively associated $(r=.188 p=0.001)$ with social support from close people living in the local community and born in the United States

Univariate regression models were conducted to predict NA and SA separately with length of duration of stay in the United States Results of the regression analysis are presented in Table 4, which includes unstandardized model coefficients (B), and associated errors (SE B), standardized regression coefficients $(\beta)$, and $t$-statistics $(t)$, significance values (Sig.) for the predictor variables. The $\mathrm{R}^{2}=0.013$ in model 1 suggests that $1.3 \%$ of the variability in the NA among international students was predicted by duration of the stay in the United States. In this case duration of stay in the United States was found to be a significant predictor for NA among international students $(p<0.05)$. However, duration of stay in the United States was not found to be a significant predictor of SI $(p=0.246)$. 
Table 2: Pairwise comparison for sources of social support from close people living in the home country, close people residing in the United States that were originally from the home country, close people residing in the United States that were originally from other countries, and close people living in the local community and born in the United States. Mean Difference (Std. error)[Cohen's $d$ ]

\begin{tabular}{|c|c|c|c|c|}
\hline Social support form & A & B & $\mathrm{C}$ & D \\
\hline $\begin{array}{l}\text { Close people living in the } \\
\text { home country (A) }\end{array}$ & - & $4.128^{*}(.468)[0.54]$ & $7.838^{*}(.488)[1.08]$ & $7.881 *(.541)[1.05]$ \\
\hline $\begin{array}{l}\text { Close people residing in the } \\
\text { United States that were } \\
\text { originally from the home } \\
\text { country(B) }\end{array}$ & - & - & $3.710 *(.498)[0.47]$ & $3.753 *(.548)[0.46]$ \\
\hline $\begin{array}{l}\text { Close people residing in the } \\
\text { United States that were } \\
\text { originally from } \\
\text { other countries (C) }\end{array}$ & - & - & - & $\begin{array}{r}.043(.447) \\
{[-]}\end{array}$ \\
\hline $\begin{array}{l}\text { Close people living in local } \\
\text { community and born in the } \\
\text { United States (D) }\end{array}$ & - & - & - & - \\
\hline
\end{tabular}

Table 3. Pearson Correlation between four sources of social support (close people living in the home country, close people residing in the United States that were originally from the home country, close people residing in the United States that were originally from other countries, and close people living in local community and born in the United States) and duration of stay in the United States.

\begin{tabular}{|c|c|c|c|c|c|}
\hline Variables & $A$ & B & $\mathrm{C}$ & D & $\begin{array}{l}\text { Duration of } \\
\text { Stay in the } \\
\text { United } \\
\text { States }\end{array}$ \\
\hline Close people living in the home country (A) & 1 & $.371^{*}$ & $.251^{*}$ & $.143^{* *}$ & $-.139 * *$ \\
\hline $\begin{array}{l}\text { Close people residing in the United States that } \\
\text { were originally from the home country }(B)\end{array}$ & - & 1 & $.340^{*}$ & $.248^{*}$ & .031 \\
\hline $\begin{array}{l}\text { Close people residing in the United States that } \\
\text { were originally from other countries }(C)\end{array}$ & - & - & 1 & $.462^{*}$ & .018 \\
\hline $\begin{array}{l}\text { Close people living in local community and born } \\
\text { in the United States (D) }\end{array}$ & - & - & - & 1 & $.188^{* *}$ \\
\hline
\end{tabular}

${ }^{*} p<001 .{ }^{* *} p=<0.05$

Table 4. Parameter Estimates from the final regression model for negative affectivity (model 1$)$ and social inhibition (model 2) as predicted by length of stay in the United States $(n=328)$.

\begin{tabular}{|c|c|c|c|c|c|c|c|}
\hline \multirow[t]{2}{*}{ Model } & & \multirow{2}{*}{ Adjusted $r^{2}$} & \multicolumn{2}{|c|}{$\begin{array}{l}\text { Unstandardized } \\
\text { Coefficients }\end{array}$} & \multirow{2}{*}{$\begin{array}{l}\begin{array}{l}\text { Standard } \\
\text { Coefficients }\end{array} \\
\text { Beta } \\
\end{array}$} & \multirow{2}{*}{$\mathbf{T}$} & \multirow{2}{*}{ p-value } \\
\hline & & & B & $\begin{array}{l}\text { Std. } \\
\text { Error }\end{array}$ & & & \\
\hline \multirow[t]{3}{*}{1} & Negative Affectivity & .013 & & & & & \\
\hline & Constant & & 17.064 & .532 & & 32.089 & .000 \\
\hline & $\begin{array}{l}\text { The length of Stay in } \\
\text { the United States }\end{array}$ & & .262 & .113 & .127 & 2.318 & .021 \\
\hline \multirow[t]{3}{*}{2} & Social Inhibition & .001 & & & & & \\
\hline & Constant & & 18.413 & .521 & & 35.357 & .000 \\
\hline & $\begin{array}{l}\text { The length of Stay in } \\
\text { the United States }\end{array}$ & & .129 & .111 & .064 & 1.161 & .246 \\
\hline
\end{tabular}




\section{CONCLUSIONS}

Despite the increase in the prevalence of international students in American colleges, the unique concern of this population is commonly overlooked (Mori, 2000, Zhang \& Goodson, 2011). To improve the literature in this field and address the unique concerns international students face, this study analyzed international students at a university from the southwestern region. This study examined four sources of social support among international students and the authors proposed the extended definition of social support for international students for future research. It is important to note that while House's (1981) definition addresses four types of social support and has been used and operationalized in numerous studies. Even though the traditional model of social support has been used with research pertaining to international students, none has discussed the importance of the source of social support (Lee, koeske, \& Sales, 2004; Poyrazli, Kavanaugh, Baker, \& Al-Timimi, 2004). The current study suggests the sources from where an international student gets of social support vary. In general, international students highly depend on close people living in the home country and least from the close people living in the local community and born in the United States. The result also suggests the shifts in these sources of social support. As the duration of stay increases, international students depend highly on close people living in the local community and born in the United States instead of close people living in the home country. All these dynamics and in-depth definition of social support in this study is important and can reflect greater specificity (context) in future research findings.

Previous studies suggest social support mitigates the adverse stress caused by migration from one country to another (Schindler 1999; Ritsner, Modai, \& Ponizovsky, 2000). In the case of international students, stress does not only come from migrating, but also from being a college student (Mori, 2000). With a long history of dealing with international students, many American universities/colleges have developed systems to provide social support such as having host family programs, international and American student friendship programs, and an international student office and international student clubs; however, language barriers together with cultural barriers prevent international students to seek social support from in and outside of these programs (Brisset et al., 2010). Although many universities have begun to promote mental health among the student population by establishing wellness and counseling centers, due to cultural differences in beliefs about mental health, associated stigma, and unfamiliarity of the resources, international students have been noted to underuse such services (Aubrey, 1991; Bradley et al., 1995; Brinson \& Kottler, 1995). Because of underutilization of mental health services and 
social support, international students might be facing severe mental health problems, without being aware.

Lack of social support may lead to increased risk for aforementioned health related problems and negative affectivity towards everyday life (Holttum, 2015). Also, in this study, using the cutoffs for the Type D personality scales, $51.2 \%(n=168)$ were considered Type D for NA and $57.3 \%(n=188)$ were considered Type $\mathrm{D}$ for SI. This is high compared to the study conducted among counterpart American Students $(31 \%=$ NI, 38\% $=\mathrm{SI}$ ) in another study by Branscum et al (2014). The results from current study revealed that the more time international student spends in the United States, the greater possibility of experiencing negative affectivity towards life events they will have. Current literature lacks empirical findings that attend to the unique dynamics of social support transition and Type D personality among the international student population. However, for some students, an increased duration of stay in the United States may also increase exposure to harmful sources of psychosocial stress, including racial and anti-immigrant discrimination (Lee, O'Neill, Ihara, \& Chae, 2013). This could also add negative affectivity towards their life. Similarly, when social support for international students starts to diminish from close people living in the home country as their duration of stay in the United States increases, the negative feelings such as sadness, disappointment, resentment, guilt, and painful feelings of isolation might augment (Sandhu \& Asrabadi, 1994). This demands the importance of learning the dynamics of social support and duration of stay in the United States for international students.

\section{LIMITATIONS}

There are several caveats of this study to be noted. First, this study used a self-reported questionnaire. When self-reporting, participants can have the tendency to report general positivity and substantially overlapping optimism, instead of actual conditions. The second limitation to this study is the crosssectional nature of the design, which prevents researchers from establishing directionality and causality of variables. Even though a relationship between duration of stay in the United States and NA was reported, it is not possible to determine causality between these two variables, without tracking the same international students throughout a period of time. A third limitation includes the use of a convenience sample. The sample consists of only international students at the University from the southwestern region. Those students might have different exposure compared to an international student who arrived in other regions. This could introduce a sampling bias. Ideally, utilizing higher sample size and sampling from different regions would have allowed the researcher to better generalize the results to the overall population. Finally, this is the first time the social support questionnaire has 
been tested. During factor analysis, subscale assessing social support from people living in the home country had 2-factor solutions. However, after closely analyzing the factor loadings there was no obvious cluster for the 2factor solution, thus, further analysis was considered without removing any items from this subscale. Future researchers have an opportunity to clarify these issues.

\section{IMPLICATION AND FUTURE RESEARCH}

This study is characterized by several strengths that can contribute to the existing literature. First, the extended definition of social support to fit the need of international students is unique and the most important strength of this study. Also, the instrument developed in this study could accurately measure the social support of the international students as it measures multiple aspects of social support. Understanding different sources of social support can help in designing effective health promotion interventions for enhancing social support and positive mental health. In addition, a similar questionnaire could be developed to assess social support among any international population, as the four sources presented in the questionnaire in this study are applicable to most immigrant populations in general. The study represented responses from international students from 72 countries. Being representative of a large number of countries, the results of this study may be more generalizable compared to other studies (Atri, Sharma, \& Cottrell, R. 2007; Brisset, Safdar, Lewis, \& Sabatier, 2010; Lee, Koeske, \& Sales 2004; Wei et al., 2007), which focus on international students from a single nation of origin. As mentioned above duration of stay is an important aspect of acculturation for international students, which could have a significant impact on sources of social support they seek. This concept was integrated into the study and the results were reported that the selection of sources of social support varied as the duration of stay in the United States varied. Another important aspect of social support and mental health is the personality. In this study, we incorporated Type D personality to explore if individual's personality changes with duration of stay. The results indicated that NA was expected to increase with duration of stay, but the duration of stay did not have any statistically significant effect on SI.

The results from this study provide a strong basis for using the extended definition of social support to fit the need of international students. Although parsimonious issues of the new model could be contested, it is utterly important to understand sources of social support of international students to provide effective interventions. Results from the study suggest the duration of stay plays an important role in understanding changing dynamics of social support over time. Future research incorporating a longitudinal study design focusing on changes in social support and mental 
health is warranted. In addition, studies that can include both physical and mental health could provide a more comprehensive picture of the overall health. Future directions should explore, understand, and promote other factors in addition to social support to enhance overall health and positive experience of international students in the United States.

\section{REFERENCES}

Atri, A., Sharma, M., \& Cottrell, R. (2007). Role of social support, hardiness, and acculturation as predictors of mental health among international students of Asian Indian origin. International Quarterly of Community Health Education, 27(1), 59-73. doi:10.2190/IQ.27.1.e

Aubrey, R. (1991). International students on campus: A challenge for counselors, medical providers, and clinicians. Smith College Studies in Social Work, 62(1), 20-33. http://dx.doi.org/10.1080/00377319109516697

Bhochhibhoya, A., Collado, M., Branscum, P., \& Sharma, M. (2014). The role of global mental health and Type D personality to predict alcohol use among a sample of college students. Alcoholism Treatment Quarterly, 33(3), 283295. http://dx.doi.org/10.1080/07347324.2015.1050932

Bradley, L., Parr, G., Lan, W. Y., Bingi, R., \& Gould, L. J. (1995). Counseling expectations of international students. International Journal for the Advancement of Counselling, 18(1), 21-31. doi: 10.1007/BF01409601

Branscum, P., Bhochhibhoya, A., \& Sharma, M. (2014). The role of emotional intelligence in mental health and Type D Personality among young adults. International Quarterly of Community Health Education, 34(4), 351365. doi: 10.2190/IQ.34.4.e.

Brinson, J. A., \& Kottler, J. A. (1995). Minorities' underutilization of counseling centers' mental health services: A case for outreach and consultation. Journal of Mental Health Counseling, 17(4), 371-385.

Brisset, C., Safdar, S., Lewis, J. R., \& Sabatier, C. (2010). Psychological and sociocultural adaptation of university students in France: The case of Vietnamese international students. International Journal of Intercultural Relations, 34(4), 413-426. http://dx.doi.org/10.1016/j.ijintrel.2010.02.009

Bruce, G., Curren, C., \& Williams, L. (2012). Type D personality, alcohol dependence, and drinking motives in the general population. Journal of Studies on Alcohol and Drugs, 74(1), 120-124. http://dx.doi.org/10.15288/jsad.2013.74.120

Cohen, J. (1992). A power primer. Psychological Bulletin, 112(1), 155.

Cohen, J., Cohen, P., West, S. G., \& Aiken, L. S. (2013). Applied multiple regression/correlation analysis for the behavioral sciences. Mahwah, NJ: Lawrence Erlbaum Associates

Cohen, S., Janicki-Deverts, D., \& Miller, G. E. (2007). Psychological stress and disease. The Journal of the American Medical Association, 298(14), 16851687. doi:10.1001/jama.298.14.1685.

Cohen, S., Mermelstein, R., Kamarck, T., \& Hoberman, H. M. (1985). Measuring the functional components of social support. In I.G. Sarason, \& B.R. Sarason, 
(Eds), Social support: Theory, research and applications (pp. 73-94). The Hague, Netherlands: Martinus Niijhoff.

Comrey, A. L., \& Lee, H. B. (2013). A first course in factor analysis. Hillsdale, NJ: Lawrence Erlbaum Associates

Das, A. K., Chow, S. Y., \& Rutherford, B. (1986). The counseling needs of foreign students. International Journal for the Advancement of Counselling, 9(2), 167-174. doi: 10.1007/BF00129411

Denollet, J., Rombouts, H., Gillebert, T. C., Brutsaert, D. L., Sys, S. U., Brutsaert, D. L., \& Stroobant, N. (1996). Personality as independent predictor of longterm mortality in patients with coronary heart disease. The Lancet, 347(8999), 417-421.

Denollet, J., Sys, S. U., \& Brutsaert, D. L. (1995). Personality and mortality after myocardial infarction. Psychosomatic Medicine, 57(6), 582-591.

Dilorio, C. K. (2006). Measurement in health behavior: Methods for research and evaluation (Vol. 1). San Francisco, CA: John Wiley \& Sons.

Emons, W. H., Meijer, R. R., \& Denollet, J. (2007). Negative affectivity and social inhibition in cardiovascular disease: Evaluating Type-D personality and its assessment using item response theory. Journal of Psychosomatic Research, 63(1), 27-39. doi: 10.1016/j.jpsychores.2007.03.010

Gilmour, J., \& Williams, L. (2012). Type D personality is associated with maladaptive health-related behaviours. Journal of Health Psychology, 17(4), 471-478. doi:10.1177/1359105311423117

Holttum, S. (2015). Students, inclusion, help-seeking and compassionate caring. Mental Health Social Inclusion Mental Health and Social Inclusion, 19(2), 61-67. http://dx.doi.org/10.1108/MHSI-02-2015-0005

House, J. S. (1981). Work, stress, and social support. Reading, MA: AddisonWesley.

Institute of International Education. (2015). Open Doors 2015 - International Student Data Highlights. Retrieved from http://www.iie.org/Research-andPublications/Open-Doors/Data/International-Students/Infographic

Jung, E., Hecht, M. L., \& Wadsworth, B. C. (2007). The role of identity in international students' psychological well-being in the United States: A model of depression level, identity gaps, discrimination, and acculturation. International Journal of Intercultural Relations, 31(5), 605-624. http://dx.doi.org/10.1016/j.ijintrel.2007.04.001

Lee, J. S., Koeske, G. F., \& Sales, E. (2004). Social support buffering of acculturative stress: a study of mental health symptoms among Korean international students. International Journal of Intercultural Relations, 28(5), 399-414. http://dx.doi.org/10.1016/j.ijintrel.2004.08.005

Lee, S., O’Neill, A. H., Ihara, E. S., \& Chae, D. H. (2013). Change in self-reported health status among immigrants in the United States: associations with measures of acculturation. PloS One, 8(10), e76494. http://dx.doi.org/10.1371/journal.pone.0076494

Leong, F. T. L. \& Chou, E. L. (1996). Counseling international students. In P. B. Pedersen, J.G. Draguns, W.J. Lonner, \& J.T. Trimble (Eds.), Counseling across cultures (pp. 210-242). Thousand Oaks, CA: Sage. 
Mallinckrodt, B., \& Leong, F. T. L. (1992). International graduate students, stress, and social support. Journal of College Student Development, 33(1), 71-78.

McClure, J. W. (2007). International graduates' cross-cultural adjustment: Experiences, coping strategies, and suggested programmatic responses. Teaching in Higher Education, 12(2), 199-217. http://dx.doi.org/10.1080/13562510701191976

Mols, F. \& Denollet, J. (2010). Type D personality in the general population: a systematic review of health status, mechanisms of disease, and work-related problems. Health and Quality of Life Outcomes, 8(9). doi: 10.1186/14777525-8-9

Mori, S. C. (2000). Addressing the mental health concerns of international students. Journal of Counseling \& Development, 78(2), 137-144.

National Association of Foreign Student Advisers. (2014). The international student economic value tool. Retrieved from http://www.nafsa.org/explore_international_education/impact/data_and_stat istics/the international_student_economic_value_tool/

National Science Foundation. (2008). Chapter 2: Higher education in science and engineering. Retrieved from http://www.nsf.gov/statistics/seind08/c2/c2h.htm\#c2sh4

Pedersen, P. B. (1991). Counseling international students. The Counseling Psychologist, 19(1), 10-58

Poyrazli, S., Kavanaugh, P. R., Baker, A., \& Al-Timimi, N. (2004). Social Support and demographic correlates of acculturative stress in international students. Journal of College Counseling, 7(1), 73-82.

Ritsner, M., Modai, I., \& Ponizovsky, A. (2000). The stress-support patterns and psychological distress of immigrants. Stress and Health, 16(3), 139-147.

Sandhu, D. S. (1995). An examination of the psychological needs of the international students: Implication for counselling and psychotherapy. International Journal for the Advancement of Counselling, 17(4), 229-239. doi:10.1007/BF01407739

Sandhu, D. S., \& Asrabadi, B. R. (1994). Development of an acculturative stress scale for international students: Preliminary findings. Psychological Reports, 75(1), 435-448. doi: 10.2466/pr0.1994.75.1.435

Sawir, E., Marginson, S., Deumert, A., Nyland, C., \& Ramia, G. (2008). Loneliness and international students: An Australian study. Journal of Studies in International Education, 12(2), 148-180. doi:10.1177/1028315307299699

Schiffer, A. A., Pedersen, S. S., Widdershoven, J. W., Hendriks, E. H., Winter, J. B., \& Denollet, J. (2005). The distressed (Type D) personality is independently associated with impaired health status and increased depressive symptoms in chronic heart failure. European Journal of Cardiovascular Prevention \& Rehabilitation, 12(4), 341-346. doi:10.1097/01.hjr.0000173107.76109.6c

Schindler, R. (1999). Immigration, Stress, and Readjustment. International Migration Review, 33(2), 505-506. doi: 10.2307/2547719

Schuster, T. L., Kessler, R. C., \& Aseltine Jr, R. H. (1990). Supportive interactions, negative interactions, and depressed mood. American Journal of Community Psychology, 18(3), 423-438. doi: 10.1007/BF00938116 
Seeman, T. E., Berkman, L. F., Blazer, D., \& Rowe, J. W. (1994). Social ties and support and neuroendocrine function: the MacArthur studies of successful aging. Annals of Behavioral Medicine. 16(2), 95-106

Smith, R. A., \& Khawaja, N. G. (2011). A review of the acculturation experiences of international students. International Journal of Intercultural Relations, 35(6), 699-713. http://dx.doi.org/10.1016/j.ijintrel.2011.08.004

United Nations Educational, Scientific and Cultural Organization. (1965). UNESCO statistical yearbook. Mayenne, France: Author

Verbik, L., \& Lasanowski, V. (2007). International student mobility: Patterns and trends. World Education News and Reviews, 20(10), 1-16.

Wei, M., Heppner, P. P., Mallen, M. J., Ku, T. Y., Liao, K. Y. H., \& Wu, T. F. (2007). Acculturative stress, perfectionism, years in the United States, and depression among Chinese international students. Journal of Counseling Psychology, 54(4), 385. http://dx.doi.org/10.1037/0022-0167.54.4.385

Williams, L., O'Connor, R. C., Howard, S., Hughes, B. M., Johnston, D. W., Hay, J. L., \& O'Carroll, R. E. (2008). Type-D personality mechanisms of effect: the role of health-related behavior and social support. Journal of Psychosomatic Research, 64(1), 63-69. http://dx.doi.org/10.1016/j.jpsychores.2007.06.008

Yeh, C. J., \& Inose, M. (2003). International students' reported English fluency, social support satisfaction, and social connectedness as predictors of acculturative stress. Counselling Psychology Quarterly, 16(1), 15-28. http://dx.doi.org/10.1080/0951507031000114058

Zhang, J., \& Goodson, P. (2011). Predictors of international students' psychosocial adjustment to life in the United States: A systematic review. International Journal of Intercultural Relations, 35(2), 139-162. http://dx.doi.org/10.1016/j.ijintrel.2010.11.011

Zhao, Y., Jindal-Snape, D., Topping, K., \& Todman, J. (2008). Theoretical models of culture shock and adaptation in international students in higher education. Studies in Higher Education, 33(1), 63-75. http://dx.doi.org/10.1080/03075070701794833

AMIR BHOCHHIBHOYA, MS, MBA, CHES is a graduate student in the Department of Health and Exercise Science at the University of Oklahoma. Email: amirkb@ou.edu

YUE DONG, MA is a graduate student in the Department of Anthropology at the University of Oklahoma. Email: Yue.Dong-1@ou.edu

PAUL BRANSCUM, PhD, RD, is an Assistant Professor of Health and Exercise Science at the University of Oklahoma. Email: pbranscum@ou.edu

Manuscript submitted: March 25, 2016

Manuscript revised: May 31, 2016 Accepted for publication: October 14, 2016 